\title{
Does Wrongful Conviction Lower Deterrence?
}

\author{
Lando, Henrik
}

Document Version

Final published version

Publication date:

2004

\section{License \\ CC BY-NC-ND}

Citation for published version (APA):

Lando, H. (2004). Does Wrongful Conviction Lower Deterrence?

Link to publication in CBS Research Portal

\section{General rights}

Copyright and moral rights for the publications made accessible in the public portal are retained by the authors and/or other copyright owners and it is a condition of accessing publications that users recognise and abide by the legal requirements associated with these rights.

\section{Take down policy}

If you believe that this document breaches copyright please contact us (research.lib@cbs.dk) providing details, and we will remove access to the work immediately and investigate your claim. 


\section{LEFIC}

Copenhagen Business School

DK-2000 Frederiksberg

\section{Center for Law, Economics and Financial Institutions at CBS}

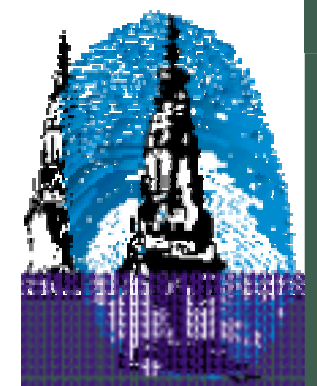

LEFIC WORKING PAPER 2004-09

Does Wrongful Conviction Lower Deterrence?

Henrik Lando

www.cbs.dk/LEFIC 
Does Wrongful Conviction Lower Deterrence?

Henrik Lando ${ }^{1}$

\begin{abstract}
The traditional answer is affirmative, based on the idea that wrongful conviction lowers a person's pay-off for being innocent without affecting the pay-off for being guilty. However, this view fails to distinguish between mistake about identity and mistake about the act. For mistake about identity the traditional view is incorrect, since a person who commits a criminal act will not thereby eliminate the risk of being convicted of someone else's crime. Conviction of the wrong person may still have an effect on deterrence, but the effect can be positive as well as negative, and will tend to be small, mainly because the risk of wrongful conviction is shared between many people.

When the court wrongly assesses the act committed by the defendant, the traditional view is correct when the choice set of the offender is binary, while the effect on deterrence is more likely to be positive when the choice set is continuous.
\end{abstract}

\title{
1. Introduction
}

According to the traditional view, the value of avoiding wrongful conviction stems in part from the effect on deterrence ${ }^{2}$. R. Posner (1999, p. 1484) formulates this view as follows:

'To see how accuracy in fact-finding relates to deterrence, notice that the expected cost of punishment ... is actually the difference between the expected cost of punishment if one commits a crime... and the expected cost of punishment if one does not commit a crime... The more accurate the process of determining guilt is, the less random punishment will be, and so the greater will be the law's deterrent effect. To put this point differently, greater accuracy in the determination of guilt increases the returns to being innocent.

The point is not limited to criminal law. It applies to all areas of law in which deterrence of unlawful behavior is an important objective. It shows what a good investment, expenditures on evidence can be'.

It will be argued that this view is incorrect for conviction of the wrong person and only partly correct for the case where the court wrongly assesses the defendant's act. The example where person A considers robbing a bank may illustrate: If A abstains from robbing the bank, A will not risk conviction of the particular act, since there will then be no harm done and no investigation. Wrongful conviction may still occur; A may e.g. be wrongly convicted of a

\footnotetext{
${ }^{1}$ Henrik Lando is Professor of Law and Economics at Copenhagen Business School, Denmark. I wish to thank Mitchell Polinsky, Richard Posner, Eric Rasmusen, Steven Shavell, a referee, and participants at the American Law and Economics Association Meeting in New York (2005) for useful comments.

${ }^{2}$ Note that the issue in the present article is neither the value of accuracy as such nor the optimal standard of proof, but the effect of an increased number of wrongful convictions, i.e. the effect of one consequence of changing the level of accuracy or the standard of proof.
} 
robbery committed by someone else, but this may occur whether or not A robs the bank, and so this possibility does not directly affect A's incentive ${ }^{3}$.

As this argument holds for any crime that produces tangible harm, for which it will be clear that the crime has not been committed, such as e.g. murder, assault and robbery, it is apparent that the traditional view fails to apply to this important category of crimes. However, this does not mean that conviction of the wrong person cannot lower deterrence as it may do so in other ways than suggested by the traditional view. For example, if A risks being imprisoned for a crime committed by someone else, A may be less deterred by the prospect of being imprisoned for robbing the bank, or A may consider that if he or she does not rob the bank, someone else will, and that suspicion may then fall on A. Or, if A is wrongfully convicted of a crime committed by someone else, investigation of the crime is likely to end, which will lower the likelihood of the offender being caught.

On the other hand, there are also circumstances under which conviction of the wrong person may increase deterrence. For example, if A robs the bank and is convicted of it, his or her probability of being wrongly convicted in the future is likely to increase due to prejudice against defendants with a prior conviction. This will increase the effective sanction of robbing the bank, as will the fact that sanctions tend to be higher for repeat offenses.

In any event, most indirect effects, whether positive or negative, are likely to be insignificant as the probability of any individual being wrongfully convicted is low, since the number of wrongful convictions is relatively small, and many people share the risk.

While the traditional view does not apply to conviction of the wrong person, it may be correct for wrongful assessment of the act committed. In the example, if A robs the bank using a toy gun or a real gun, he or she may consider the possibility that the court will mistake the toy gun for a real gun. This possibility may increase the incentive for him or her to use a real gun, as claimed by the traditional view. However, this effect rests on there being only two discrete options. A may choose not to use any weapon at all, or to abstain from the crime, if using a toy gun implies the risk of too great a sanction. As a general point, when a potential offender can vary his or her level of compliance or degree of care, the possibility of wrongful conviction may lead him or her to comply more, or to act with a higher degree of care, in order to lower the risk of wrongful conviction.

These points will be discussed in the following order. In the next section, the example of speeding in traffic will illustrate the difference between mistake about the act and mistake about identity, and demonstrate that mistake about identity does not directly affect deterrence. Three indirect effects are then analyzed, and it is concluded that they may either increase or decrease deterrence, and are likely to be of minor significance, except under particular circumstances. An analysis then follows of when the traditional view needs to be qualified for mistake about the act, and a conclusion including some broader implications of the analysis ends the article.

\section{Mistake about the Act versus Mistake about Identity}

The example of speeding in traffic ${ }^{4}$ may illustrate the distinction between a mistake about the act and a mistake about identity, since for this act both types of mistake may occur: speeding may be measured inaccurately and license plates may be difficult to read from police photos.

\footnotetext{
${ }^{3}$ The bank may be unlikely to be robbed by another person on the same day as A robs it; this objection will be analyzed below.

${ }^{4}$ This example is partly derived from Posner (1999).
} 
For the case of mistake about the act, i.e. in the case of inaccurate measurement of speed, consider the case where the driver's choice is binary, i.e. where the choice is to drive either too fast or at a legal speed. Denote by $\varepsilon_{1}$ the probability of a false negative and by $\varepsilon_{2}$ the probability of a false positive. The expected sanction from speeding is then $\left(1-\varepsilon_{1}\right) s$, while $\varepsilon_{2} s$ is the expected sanction from not speeding. It follows that the driver speeds if his or her benefit exceeds the net expected sanction $\left(1-\varepsilon_{1}-\varepsilon_{2}\right) s$. This presents the traditional view of the effect of wrongful conviction on deterrence ${ }^{5}$; it implies that false negatives and false positives both lower deterrence, and to the same extent.

For the case of mistake about identity, the same logic does not apply, as can be seen as follows. If speed is measured correctly (i.e. $\varepsilon_{2}$ equals zero), and if $\varepsilon_{3}$ denotes the probability of being sanctioned for another person's speeding, the expected sanction if one speeds will be $\left(1-\varepsilon_{1}\right) s+\varepsilon_{3} s$, while the expected sanction if one does not speed will be $\varepsilon_{3} s$, yielding a net expected sanction of $\left(1-\varepsilon_{1}\right) s$. The net expected sanction is hence unaffected by the risk of wrongful conviction; the risk lowers the pay-off, not only for being guilty but also for being innocent.

As nothing in this argument is specific to the example of speeding in traffic, it is clear that convicting the wrong person does not affect deterrence in the way suggested by the traditional view.

\section{Does Convicting the Wrong Person Affect Deterrence in Other Ways?}

Three effects are particularly worth analyzing ${ }^{6}$ :

1) Wrongful convictions may end investigations, thereby lowering the probability that the true identity of the offender will be convicted.

2) A potential offender may not want to forego a crime opportunity, since others may then seize the opportunity, in which case the former may be wrongly convicted.

3) The prospect of being (correctly) sanctioned may seem less threatening when there is a possibility that the sanction will come on top of a wrongful sanction.

\subsection{Investigations May End When an Innocent Person Is Sanctioned}

If a person decides to commit a murder and some other person is wrongfully convicted, investigation of the case may end, since the prosecution will have little incentive to continue

\footnotetext{
${ }^{5}$ The idea behind this result seems to have been first noted by Posner (2000). The result has been applied by many authors, e.g. Bar-Gil (2004), Kaplow and Shavell (1994), Kaplow (1994), Png (1986), Polinsky and Shavell (2000), and Strandburg (2003).

${ }^{6}$ Other effects exist, but seem to be of minor importance. For example, if a person commits a crime at a given time and place and is apprehended, this may provide him or her with an alibi, which precludes wrongful conviction of a crime committed at nearly the same time at a distant place. Also, if the person goes to jail, this in itself provides an alibi which precludes wrongful conviction of crimes committed outside the prison. Finally, it may be argued that wrongful conviction lowers the stigma (Rasmusen (1996)) and hence the deterrent effect of correct conviction.
} 
investigating the case. Consequently, wrongful conviction may lower the probability that the actual offender is convicted, and may thereby indirectly lower deterrence.

However, the police may also drop the case in the case of an acquittal, especially if it is impossible to have two trials against the same person for a given offense. If the police drop the case after an acquittal, there may be no one with the incentive to investigate further or to claim that the actual offender has not been found, while in the case of a wrongful conviction, the wrongly convicted, or the people or organizations safeguarding the interests of the convicted, have the incentive.

More importantly, when taken off a given case after a guilty verdict, the police will be assigned to other tasks, which means that the argument that ending investigations lowers deterrence hinges on the (unfounded) assumption that the police are better employed pursuing the given case instead of other cases ${ }^{7}$.

Furthermore, the effect appears likely to be small under most circumstances. Thus, for a given crime, denote by $Z$ the number of offenses, by $\mathrm{Y}$ the number of wrongful convictions, by $\Delta p$ the increase in the probability that investigations will end when there is a wrongful conviction, and by $\eta$ the probability that these investigations would have been successful. Then, if it were possible to eliminate all wrongful convictions, the decline in the number of wrongful convictions would be $Y$, and for each correction of a wrongful conviction, the increase in the probability of apprehending the actual offender would be $\Delta p \times \eta . Y \times \Delta p \times \eta$ more offenders would then be convicted, implying that the expected sanction would increase by $(Y / Z) \times \Delta p \times \eta \times s$. Then, even if $Y / Z$ is assumed to be high, such as $10 \%$ (which is very high for most kinds of serious crime where convictions are often based on good evidence), and even if $\Delta p \times \eta$ is assumed to be $30 \%$, meaning that $30 \%$ of correct acquittals prompt successful investigations leading to the actual offender (investigations that would have been ended had there been a wrongful conviction), the total effect on the expected sanction of never convicting wrongly, in itself highly unrealistic, would be in the order of three percentage points. Clearly, if attention is restricted to realistic changes in the standard of proof, the effect on deterrence will be much smaller.

On the other hand, the effect may be greater under certain special circumstances, as when an offender attempts to set someone up. The possibility of the court mistaking the identity of the offender then becomes higher than the averages just given, and the offender's incentive may then conceivably be affected by his or her expectations that a wrongful conviction will get him or her 'off the hook'. Thus, when a set up may have occurred, avoiding wrongful conviction takes on added importance. However, this kind of situation seems relatively rare in reality, and the general impression remains that the effect on deterrence is ordinarily quite small.

\subsection{Leaving a Crime Opportunity for Others}

The second effect can be illustrated by a situation in which a person strays into a dangerous neighborhood, and where a criminal, who is known by the police to operate in that neighborhood, considers mugging that person. In this situation, the criminal may consider that if he or she does not mug the person, suspicion may still fall on him or her in the event that somebody else takes advantage of the opportunity. The point is that by not committing the crime, he or she increases (by one) the number of crimes committed by others, and hence the

\footnotetext{
${ }^{7}$ If this is the case, there may be a way to ensure that cases are not dropped after a guilty verdict.
} 
number of crimes for which he or she may be wrongly convicted ${ }^{8}$. Clearly, the possibility of wrongful conviction may then act as an inducement for him or her to commit the crime. Again, however, the effect seems to be of limited importance under ordinary circumstances. It relies on three assumptions. First, that by committing a crime, an offender diminishes the number of crime opportunities open to others, and that others are restrained from illegal conduct by the number of crime opportunities open to them. Second, it relies on the assumption that the number of potential suspects is limited such that each potential suspect faces a significant probability of wrongful conviction. This assumption may perhaps be valid in certain situations, such as in the mugging example, but note that even in this example, if there are e.g. ten other possible suspects in the neighborhood, and the probability that somebody will be wrongfully convicted is $10 \%$, and the probability that somebody else will commit the crime is $50 \%$, the overall probability of wrongful conviction is only .005 . Under most ordinary circumstances, this probability seems likely to be much lower. And finally, as the third assumption, the first potential offender must believe that other potential criminals will not be deterred by the prospect of being sanctioned. If this belief is correct, the crime will be committed in any event, which means that overall deterrence will not be affected by the possibility of wrongful conviction ${ }^{9}$.

\subsection{Two Sanctions May Not Be Twice As Threatening As One}

The third indirect effect is based on the notion that a potential offender may consider a prospective sanction less threatening when it may be applied on top of another sanction. For instance, a ten-year incarceration may not be felt twice as much as a five-year one, e.g. because an offender may underestimate the difference between five and ten years in prison, or because the loss of reputation and the damage to the prospect of returning to a normal life may be the same whether the total sanction is a five- or a ten-year sentence. In other words, marginal disutility may decrease with the size of the total sanction, and sanctions may therefore enter sub-additively into the utility function of the potential offender. On the other hand, when the sanction is monetary, risk aversion implies that the marginal disutility of a sanction increases with its size, and the effect on deterrence is then positive rather than negative ${ }^{10}$. As mentioned, this will also be the case if a repeat offender is treated more severely than a first-time offender.

Thus, the overall effect on deterrence is ambiguous.

However, the main point to be stressed here is that the effect, whether positive or negative, is likely to be of little quantitative importance. Under most normal circumstances, an innocent person's risk of being wrongfully convicted is small. In the example of homicide, if the murder rate is five per 100,000 people $^{11}$, then even if the sanction were, as an extreme case, applied at random, the probability of being wrongfully convicted would only be five in 100,000. So, even if legal verdicts were wholly arbitrary, the probability of wrongful conviction, and hence also the consequence of a falling marginal disutility of sanctions, would be small. In reality,

\footnotetext{
${ }^{8}$ The situation is analyzed by Schrag and Scotchmer (1994). They investigate the role of evidence rules aimed at limiting the effect of possible prejudice on the part of the courts.

${ }^{9}$ However, one can theoretically imagine bootstrap equilibria, where the prospect of wrongful conviction is also decisive for other criminals. There may then be multiple equilibria, as analyzed by Schrag and Scotchmer (1997)

${ }^{10}$ That may also be the case if the second sanction renders the offender insolvent, and if the monetary sanction is then converted into a prison sentence, while if the sanction is not converted, judgment proofness may imply that the second sanction loses some of its impact.

${ }^{11}$ This is approximately the case in the US.
} 
sanctions are of course often based on solid evidence, and hence the risk of wrongful conviction is, in the case of murder, much lower than five in 100,000. For other crimes the crime rate is higher but the rate of apprehension is then typically much lower.

Naturally, some people face a higher risk of wrongful conviction than others, e.g. due to prejudice against people with a prior criminal record, but it still seems fair to conclude that the effect of the falling marginal disutility of sanctions will under most realistic circumstances be of minor significance.

\section{When Does Mistake about the Act Lower Deterrence?}

In the example above where speed was assumed to be measured inaccurately, the traditional view was confirmed for a binary choice. However, if the potential offender's choice variable is continuous, as it is in reality for the driver, the effect may be different, as the driver may then lower $\varepsilon_{2}$ by lowering his or her speed. This was analyzed by Shavell (1987, pp. 79-82) in the context of tort law, and by Craswell and Calfee (1986) in the context of compliance with a standard. Their results were as follows. First, when legal uncertainty is not too large and under-assessment of care or compliance (in our example: over-estimation of speed) may occur, over-deterrence will be the outcome. In short, the discontinuity of the sanction at the point of perceived compliance provides an incentive to be on the safe side. Second, over-deterrence might occur when the choice set is discrete and contains more than two alternatives. For the same reason as in the continuous case, a potential offender may then have an incentive to choose an action that lowers or eliminates the possibility of wrongful conviction, i.e. he or she may have an incentive to over-comply. As a special case, he or she may not engage in the given activity at all, as emphasized by Png $(1986)^{12}$. Third, under-deterrence may occur when uncertainty is high. As intuition would suggest, when uncertainty is high, the connection between actual and measured speed becomes loose, and as the driver then cannot control the measured outcome by driving more slowly, he or she might as well increase the speed. However, the conditions under which this occurs are quite restrictive; the possibility that measurement error leads to under-deterrence is described as 'unlikely' by Shavell (1987, p. 96), and Craswell and Calfee (1986, p. 299) denote the assumptions under which over-deterrence occurs as `seemingly plausible'.

It is worth noting that these results apply not only to errors concerning the existence of a criminal act, but also to error concerning the nature of a crime. Thus, in the example already mentioned, the possibility of error may incite the robber to use a real gun (this is the case of the binary choice), but may also deter the robber from threatening with any kind of gun (i.e. the choice set may not be binary). Note that the offender may, at least in theory, be deterred from the act altogether, if abstaining from using a toy gun lowers the chances of a successful robbery. In other words, error concerning the nature of the act committed may increase deterrence $^{13}$. As another example of uncertainty concerning the nature of the act, it may be

\footnotetext{
${ }^{12}$ In the example of riding a motorcycle, Png (1986) argues that error in the assessment of care is likely to lead to too little care and to act as a tax on entering into the activity. The former result is due to his assumption that care is a binary rather than a continuous variable.

${ }^{13}$ Wrongful acquittal (believing the person only used a toy gun when in fact he or she used a real gun) will of course lower deterrence.
} 
unclear whether the defendant acted with a lack of intent or in self-defense. The question then becomes whether a person, who acted unintentionally or in self-defense, might have acted differently if he or she had contemplated the possibility of wrongful conviction ${ }^{14}$. Again, the answer will depend on whether the choice is binary, and on whether the potential offender can influence the court's perception of his or her act. For example, wrongful conviction can arise when a low level of care is mistaken for intent; this may hence be a case of a continuous choice, and the possibility of a mistake may then increase the incentive to act with care (or to not engage in the activity), to the extent that a higher degree of care lowers the risk of being found to have acted with intent ${ }^{15}$.

To conclude, wrongful conviction involving legal errors concerning whether or how an act was committed may lower deterrence in the case of binary choices, but may increase deterrence when the choice set includes more than two options. As can be seen from the examples just given, the increase may either be socially beneficial or lead to over-deterrence.

\section{Conclusion}

The main point of this article is that the traditional view concerning the effect of wrongful conviction on deterrence needs to be revised. It holds that wrongful conviction lowers deterrence by lowering the pay-off to remaining innocent, and the view hence fails to recognize that both the guilty and the innocent may be convicted of criminal acts committed by others. While the traditional logic hence does not apply to conviction of the wrong person (i.e. does not generally apply to wrongful attribution of causality), it may be argued that there are other ways in which deterrence may be affected by this kind of legal error. For example, the prospect of wrongful conviction may seem more threatening for an innocent than for a guilty person. However, such indirect effects may increase rather than decrease deterrence, e.g. when the sanction is monetary, when a repeat offender is sanctioned more heavily than a firsttime offender, and when people with a criminal record are more likely to be wrongly convicted than people with no prior offenses. Moreover, any person's risk of wrongful conviction is generally very small, not only because the event is relatively rare, but also because the risk is shared between many people.

As an overall conclusion, it is unclear whether convicting the wrong person increases or decreases deterrence, and the effect is likely to be small under ordinary circumstances.

For legal error concerning the act committed, the traditional view also needs to be qualified, as it may not apply when the potential offender can lower the risk of wrongful conviction through his or her degree of care or compliance. While the traditional view does apply to either-or choices, it is unlikely to apply to more continuous choices. This conclusion applies also to error about the nature of a crime, i.e. when uncertainty concerns an aspect of the act. In terms of broader implications, the analysis bears on the socially optimal rules of evidence and standards of proof. For example, the traditional view leads to the idea that a pro-defendant evidence rule, which increases the risk of wrongful conviction as much as it reduces the risk of wrongful acquittal, will be neutral in terms of deterrence, whereas the present analysis suggests that such a rule will unambiguously lower deterrence for an important category of crimes. Also, the analysis indicates that society's strong preference for avoiding wrongful conviction must be explained and justified by considerations other than deterrence, e.g. by a wish to avoid the unfairness of sanctioning the innocent, or, in a narrower utilitarian interpretation, by a wish

\footnotetext{
14 The issue of wrongful conviction does not arise if the person acted with intent or did not act in self-defense.

${ }^{15}$ For self-defense, the increase in 'care' will imply too little self-defense, if the level allowed by the law is adequate.
} 
to avoid imposing a harmful sanction on a person when the sanction is not justified by a gain in deterrence.

\section{References}

Bar-Gil, Oren. 2004, "The Efficiency of Protecting the Innocent", Working Paper, Harvard University Law School.

Craswell, Richard. \& Calfee, John. 1986, "Deterrence and Uncertain Legal Standards", Journal of Law, Economics, and Organization, vol. 2, no. 2, pp. 279-303.

Kaplow, Louis. 1994, "The Value of Accuracy in Adjudication: An Economic Analysis", Journal of Legal Studies, vol. 23, no. 1, pp. 307-401.

Kaplow, Louis. \& Shavell, Steven. 1994, "Optimal Law Enforcement with Self-Reporting of Behavior", Journal of Political Economy, vol. 102, no. 3, pp. 583-606.

Png, Ivan. 1986, "Optimal Subsidies and Damages in the Presence of Judicial Error", International Review of Law and Economics, vol. 6, no. 1, pp. 101-5.

Polinsky, Mitchell. \& Shavell, S. 2000, "The Economic Theory of Public Enforcement of Law", Journal of Economic Literature, vol. 38, no. 1, pp. 45-76.

Posner, Richard. 1999, "An Economic Approach to the Law of Evidence", Stanford Law Review, vol. 51, pp. 1477-55.

Posner, Richard. 2000, "An Economic Approach to Legal Procedure and Judicial Administration", The collected economic essays of Richard A. Posner.Volume 1.The economic structure of the law, , pp. 290-349.

Rasmussen, Eric. 1996, "Stigma and Self-Fulfilling Expectations of Criminality", Journal of Law and Economics, vol 39, pp. 519-544.

Schrag, Joel. \& Scotchmer, Suzanne. 1997, "The Self-Reinforcing Nature of Crime", International Review of Law and Economics, vol. 17, no. 3, pp. 325-35.

Schrag, Joel. \& Scotchmer, Suzanne. 1994, "Crime and Prejudice: The Use of Character

Evidence in Criminal Trials", Journal of Law, Economics, and Organization, vol. 10, no. 2, pp. 319-42.

Shavell, Steven. 1987, Economic Analysis of Accident Law, Harvard University Press, Cambridge.

Strandburg, Katherine. 2003, "Deterrence and the Conviction of Innocents", Connecticut Law Review, vol. 35, p. 1321. 